\title{
Measuring Content Validity: Students' Self-efficacy and Meaningful Learning in Massive Open Online Course (MOOC) Scale
}

\author{
Norliza Ghazali ${ }^{\mathrm{a}}$, Mohamad Sahari Nordin ${ }^{\mathrm{b}}$, Sulaiman Hashim ${ }^{\mathrm{b}}$, Suhailah \\ Hussein $^{b}$ \\ ${ }^{a}$ Universiti Putra Malaysia, Serdang, Selangor, Malaysia \\ bInternational Islamic University Malaysia, Gombak, Selangor, Malaysia \\ Corresponding e-mail: norliza.g242@gmail.com
}

\begin{abstract}
The objective of this research is to examine the content validity of students' self-efficacy and meaningful learning scale in context of Massive Open Online Course (MOOC) by using Content Validity Ratio (CVR). The research was conducted through the evaluation among 20 expert panels with purposive sampling technique. Expert panels were divided into two categories which are professional experts and field experts. Nine professional university experts involved with the respective expertise in psychology, psychometric, educational measurement and MOOC. The field experts consisted of eleven doctor of philosophy (PhD) candidates who is studying in public university in Malaysia and specializing in particular fields of study. The scale contains of two aspects which is students' self-efficacy and meaningful learning. Students' selfefficacy is conceptualized in four constructs with 35 items. Meanwhile for meaningful learning, there have five construct with 50 items. The results of the research show that the scale has a good content validity and proved that the scale has great potential to be promoted as a good scale of students' self-efficacy and meaningful learning in context of MOOC. It is suggested to apply more sophisticated statistical analysis, such as the Structural Equation Modelling for elaborating on quality items and model development.
\end{abstract}

Keywords: content validity, expert panel, self-efficacy, meaningful learning, Massive Open Online Courses (MOOC)

\section{INTRODUCTION}

Content validity refers to the process to determine how well the dimensions and elements of a concept can be successfully defined (Sekaran, 2011). The other function of content validity is to validate every item in the instrument representing each measured construct (Miller et al, 2013). Construct validity provide information or data to prove that the items in the scale are correlated and together measure the construct they are meant to measure.

In the context of psychometrics, the validity of the scale described the extent to which the scale was able to measure the construct. The more evidence of content validity such as the expert evaluation is obtained, the higher the confidence of the researcher in the validity of the instruments being constructed (Johnson, 2012). This study aims to measure content validity for students' self-efficacy and meaningful learning scale in context of Massive Open Online Course (MOOC).
Massive Open Online Course (MOOC) is a new innovation with great challenge to the traditional classroom teaching mode and also an alternative way of delivering interactive teaching and learning (Ministry of Education Malaysia, 2015). Massive and open indicate that it is offerings unlimited courses and open to everyone. Online Courses gives the impression that teaching and learning is delivered on-line and there is no limit for individuals who want to participate.

Student's self-efficacy is defined as student's perception of their own ability to perform a specific task with a certain level of proficiency (Cartwright \& Atwood 2014). Meaningful learning is a learning process that combines several teaching and learning activities, consists of active and constructive processes, which allow students to develop knowledge, reflects on the activities and articulates the information.

In this research context, expert panel evaluation is very essential to be part of this research. In 
briefly, consensus of the expert panels are the key factor for this research in order to examine content validity of students' self-efficacy and meaningful learning scale in context of MOOC.

\section{SELF-EFFICACY}

In this study, Self-efficacy in Internet-Based Learning Environment Scale (SIBLE, Yu-Li Chen, 2014) was adapted to measure students' self-efficacy in context of MOOCs. Students' self-efficacy is conceptualized in four constructs. The four constructs are described as follow:

i) Information Searching: The method of students prefer to use in information searching through the learning process in MOOCs

ii) Query: The method where the students prefer to make query when they have to make a query through the learning process in MOOCs. Formal query is the method that students use to make a query by using function in MOOCs. Informal query is the method that student tend to make a query outside from the MOOCs.

iii) Learning Process: Students' capabilities to involve in the process of learning, understanding the content, ability to do learning task and collaborate with others through the learning process in MOOCs platform.

iv) Platform Usability: Students' capabilities to use functions in MOOCs, involved in learning requirement in MOOCs and use the technological competency in MOOCs platform

\section{MEANINGFUL LEARNING}

There is another aspect in the scale which is meaningful learning. Meaningful learning scale (Din, 2010) was adapted to measure students' meaningful learning in context of MOOCs. The developed item was also based on a meaningful learning rubric template constructed by Jonassen, Peck \& Wilson (1999) in Learning with Technology: A Constructive Perspective. Meaningful learning in this study is conceptualized in five constructs which are defined as follow:

i) Cooperative Learning: Interaction among students. Interaction with expert. Social negotiation. Acceptance \& distributions of roles

ii) Active Learning: Student participation in their learning process. Learner interaction with real world technology tools. Observation \& reflection.

iii) Authentic Learning: Complexity, Higher order thinking, recognizing problems iv) Constructive Learning: Knowledge integration. Constructing mental model. Making meaning.

v) Intentional Learning: Setting own goals. Regulating own learning. Monitoring learning progress.

\section{RESEARCH METHODOLOGY}

To validate the content validity of the constructs, the quantitative approach (Lawshe, 1975; Lewis et al, 2005) was undertaken in the following manner:

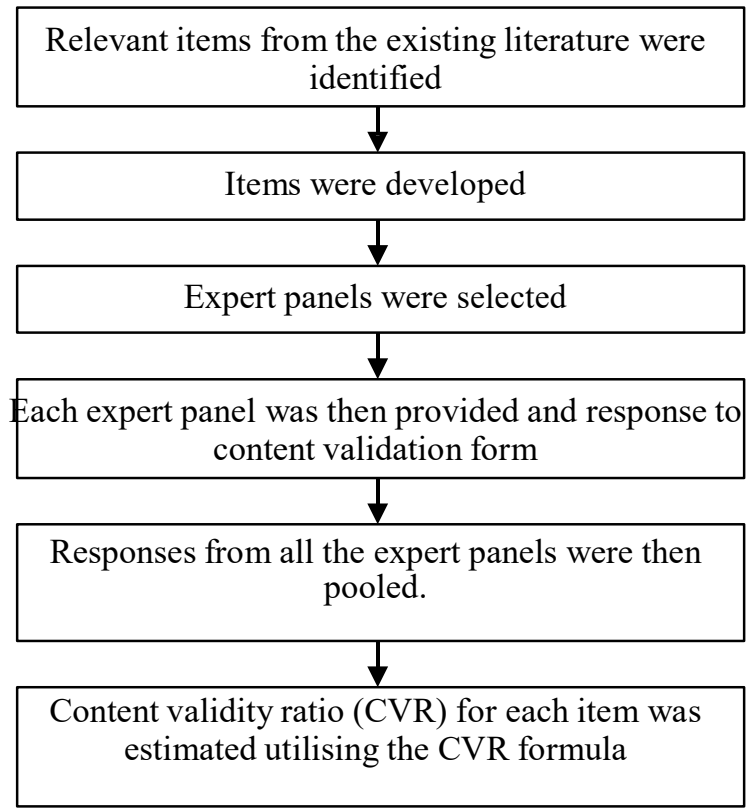

Figure 1.1 Research process

A few expert panels were invited to review the items with regard to item content representativeness of the constructs, clarity, relevance and format. A panel of experts being made up of two categories: professional experts and field experts (Rubio et al, 2003). Nine professional university experts involved with the expertise in psychology, psychometric, educational measurement, and MOOCs. All the professional experts consist of senior lecturers, lecturers or researcher at the university. The field experts consisted of eleven doctor of philosophy $(\mathrm{PhD})$ candidate who is studying in public university in Malaysia and specializing in particular fields of study.

The sampling technique used was purposive sampling, which is judgment sampling. The criteria for selecting the panel of professional experts and field experts are based on academic qualification and experiences. The researcher contacts the experts via 
telephone and emails to explain the purpose of the study, the procedures and seek their approval to participate. Although Lawshe's method only requires at least five members for the panel, the researcher has decided to include as many experts as possible to increase the value of the model (Lawshe, 1975). The total of 20 experts in this research is exceeding the recommendations from past researchers (Baheiraei, 2013; Delgado-Rico, 2012). Previous research by Norashady et al (2016) use total of 14 expert panels in order to measure the content validity of Marine Engineer Personality Inventory (MEPI) in their research.

All the expert panels were ask to indicate whether each items is 'essential', 'useful but not necessary' or not necessary' to be included in the scale to measure the construct (Cohen \& Swerdlik, 2010). The expert panel also were asked to check on the item clarity and to comment on scale instructions, item format, sentences and response options after completing the content validation form. The percentage of agreement will be compute using the following formula;

Content validation ratio (CVR),

CVR $=(\eta \mathrm{e}-\mathrm{N} / 2) /(\mathrm{N} / 2)$

ne $=$ number of panellist indicating essential,

$\mathrm{N} \quad=$ total number of panellist

CVR is a direct linear transformation from the percentage saying "essential". CVR used for measuring the content validity of the items through empirical measurements. This method is more practical from the aspect of time and costs. In addition, this method also easy to administer and only need a short time in term of implementation process (Dewi Rooslani Tojib \& Ly-Fie Sugianto, 2006). These advantages have made CVR a choice among past researchers (Baheiraei, 2013; DelgadoRico, 2012; Norashady et al (2016).

CVR was positive if more than half of the expert panels indicate the item as essential. It was 0 if only half of the expert panel indicate the item as essential and negative if less than half of the expert panel members indicate the item as essential. The CVR helps the researchers to improve on the scale and to decide which items to retain and which items to remove.

The value of CVR ranged from 0 to 1 (Lawshe, 1975; Lewis et al, 2005). CVR values obtained for each item were examined for their significance employing the standard table provided by Lawshe (1975). If the estimated CVR value was equal to or above the standard value, then the item was accepted; other-wise it was eliminated. The significance level or standard value depended upon the number of experts rating the item. The items with CVR values meeting the minimum of the standard value are retained in the final form of the test. However, in this research, the researcher decided to measure and reported only the finding of CVR value for each item.

\section{RESULT AND DISCUSSION}

The demographic profile of the profesional experts $(\mathrm{N}=9)$ shows female $(6,66.7 \%)$ dominated male experts $(3,33.3 \%)$. All of professional experts are from various universities such as Universiti Putra Malaysia, Universiti Kebangsaan Malaysia and International Islamic Universiti Malaysia. For field experts $(\mathrm{N}=11)$ distribution shows female $(8,72.7 \%)$ dominated male experts $(3,27.3 \%)$. Field experts in this study were candidate of Doctoral of Philosophy $(\mathrm{PhD})$ in psychology, measurement and evaluation, curriculum and instruction.

The overall findings showed that all the items have positive CVR value. The value of CVR ranged from 0 to 1 (Lawshe, 1975; Lewis et al, 2005). Table 1 and Table 2 show that all the CVR value of the items range from $0.000-0.800$. Only 1 item in authentic learning construct for meaningful learning that was just on the border line with CVR value 0.000 (Item 6, "I manage to synthesis learning material which provided in MOOCs"). Most of the expert panels recommended to change the word of "synthesis" to other term which is more understandable by respondents. This was due to the respondents will be the students and not every students have the knowledge and understand the definition of "synthesis".

Table 1 and Table 2 show that only Query construct in student's self-efficacy obtained CVR value above 0.500 for all the items. Item 1 ("I can use online interaction facility in MOOCs to make a query") obtained the highest CVR value in this construct $(0.800)$ followed by Item 2 ("I can use the comment function in MOOCs to make a query") with CVR value 0.700 . The other items in this construct gained CVR value 0.600 and 0.500 . The highest CVR value of the scale is 0.800 which is for Items 1 ("I can use online interaction facility in MOOCs") and Item 4 ("I can seek all the content / instructional material provided in MOOCs platform") in information searching construct, Item 1 ("I can use online interaction facility in MOOCs to make a query") for query construct, Item 8 ("I can collaborate with others through the learning process in MOOCs platform") in learning process construct and Item 2 ("I can upload assignments in MOOCs 
platform") and Item 4 ("I can manage instructional materials from MOOCs platform") in platform usability construct.

Review from expert panels recommended that almost sixty percent of the items need to be modified and revised because some of the terms which is not in compliance with Malaysian culture. Some of the items need to rephrase to make it clearer and easily understand. A few expert panels suggested to be careful and avoid cross-loading items. Each item will be revised by researcher with considering all the comment from the expert panels as preparation for pilot testing. Further analysis should be carried out to test the construct validity, convergent validity \& discriminant validity by using statistical methods.

Table 1 CVR value for students' self-efficacy in MOOC

\begin{tabular}{|c|c|c|}
\hline Construct & Item & CVR value \\
\hline Information Searching & $\begin{array}{l}\text { Item 1 } \\
\text { Item 2 } \\
\text { Item 3 } \\
\text { Item 4 } \\
\text { Item 5 } \\
\text { Item 6 } \\
\text { Item 7 }\end{array}$ & $\begin{array}{l}0.800 \\
0.400 \\
0.600 \\
0.800 \\
0.200 \\
0.400 \\
0.400\end{array}$ \\
\hline Query & $\begin{array}{l}\text { Item 1 } \\
\text { Item 2 } \\
\text { Item 3 } \\
\text { Item 4 } \\
\text { Item 5 } \\
\text { Item 6 } \\
\text { Item 7 } \\
\text { Item 8 }\end{array}$ & $\begin{array}{l}0.800 \\
0.700 \\
0.500 \\
0.600 \\
0.500 \\
0.600 \\
0.500 \\
0.600\end{array}$ \\
\hline Learning Process & $\begin{array}{c}\text { Item } 1 \\
\text { Item } 2 \\
\text { Item } 3 \\
\text { Item } 4 \\
\text { Item } 5 \\
\text { Item } 6 \\
\text { Item } 7 \\
\text { Item } 8 \\
\text { Item } 9 \\
\text { Item } 10\end{array}$ & $\begin{array}{l}0.500 \\
0.500 \\
0.500 \\
0.400 \\
0.500 \\
0.200 \\
0.600 \\
0.800 \\
0.700 \\
0.600\end{array}$ \\
\hline Platform Usability & $\begin{array}{l}\text { Item } 1 \\
\text { Item } 2 \\
\text { Item } 3 \\
\text { Item } 4 \\
\text { Item } 5 \\
\text { Item } 6 \\
\text { Item } 7 \\
\text { Item } 8 \\
\text { Item 9 }\end{array}$ & $\begin{array}{l}0.400 \\
0.800 \\
0.700 \\
0.800 \\
0.600 \\
0.700 \\
0.400 \\
0.500 \\
0.200\end{array}$ \\
\hline
\end{tabular}


Table 2 CVR value for students' meaningful learning in MOOC

\begin{tabular}{|c|c|c|}
\hline Construct & Item & CVR value \\
\hline $\begin{array}{c}\text { Cooperative } \\
\text { Learning }\end{array}$ & $\begin{array}{l}\text { Item } 1 \\
\text { Item } 2 \\
\text { Item } 3 \\
\text { Item } 4 \\
\text { Item } 5 \\
\text { Item } 6 \\
\text { Item } 7 \\
\text { Item } 8 \\
\text { Item } 9\end{array}$ & $\begin{array}{l}0.400 \\
0.700 \\
0.200 \\
0.600 \\
0.400 \\
0.700 \\
0.500 \\
0.300 \\
0.200\end{array}$ \\
\hline Active Learning & $\begin{array}{l}\text { Item } 1 \\
\text { Item } 2 \\
\text { Item } 3 \\
\text { Item } 4 \\
\text { Item } 5 \\
\text { Item } 6 \\
\text { Item } 7 \\
\text { Item } 8 \\
\text { Item } 9\end{array}$ & $\begin{array}{l}0.300 \\
0.600 \\
0.400 \\
0.500 \\
0.500 \\
0.600 \\
0.500 \\
0.500 \\
0.700\end{array}$ \\
\hline Authentic Learning & $\begin{array}{c}\text { Item } 1 \\
\text { Item } 2 \\
\text { Item } 3 \\
\text { Item } 4 \\
\text { Item } 5 \\
\text { Item } 6 \\
\text { Item } 7 \\
\text { Item } 8 \\
\text { Item } 9 \\
\text { Item } 10\end{array}$ & $\begin{array}{l}0.400 \\
0.500 \\
0.300 \\
0.500 \\
0.400 \\
0.000 \\
0.300 \\
0.500 \\
0.500 \\
0.700\end{array}$ \\
\hline Constructive Learning & $\begin{array}{l}\text { Item } 1 \\
\text { Item } 2 \\
\text { Item } 3 \\
\text { Item } 4 \\
\text { Item } 5 \\
\text { Item } 6 \\
\text { Item } 7 \\
\text { Item } 8 \\
\text { Item } 9 \\
\text { Item } 10\end{array}$ & $\begin{array}{l}0.400 \\
0.600 \\
0.200 \\
0.600 \\
0.700 \\
0.400 \\
0.400 \\
0.500 \\
0.500 \\
0.500\end{array}$ \\
\hline Intentional Learning & $\begin{array}{l}\text { Item } 1 \\
\text { Item } 2 \\
\text { Item } 3 \\
\text { Item } 4 \\
\text { Item } 5 \\
\text { Item } 6 \\
\text { Item } 7 \\
\text { Item } 8 \\
\text { Item } 9 \\
\text { Item } 10\end{array}$ & $\begin{array}{l}0.600 \\
0.600 \\
0.300 \\
0.500 \\
0.700 \\
0.700 \\
0.400 \\
0.300 \\
0.400 \\
0.600\end{array}$ \\
\hline
\end{tabular}




\section{CONCLUSIONS}

In conclusion, all the items obtained positive CVR value range between 0.000 and 0.800 . This finding showed that the items were built with a good operationalization and conceptualization. However, almost sixty percent of the items required modification and refinement in order to make the items more understandable and clear. The strength of CVR was prominent in this research when the differences in expert panel opinions could be seen clearly and easily. The researcher will revise each item with considering all the comment from the expert panels as preparation for pilot testing. The researcher suggested that all 85 items that were refined would undergo a pilot study. The results of the research show that the scale has a good content validity and proved that the scale has great potential to be proposed as a good scale of students' selfefficacy and meaningful learning in context of MOOC. The researcher plan for further investigation for validity evidence of the scale such as construct validity, convergent validity $\&$ discriminant validity. In addition, reliability test or consistency of the items will be measure to identify the internal consistency of the item. It is also suggested to apply more sophisticated statistical analysis, such as the Structural Equation Modelling for expanding on best items and to develop measurement model for students' self-efficacy and meaningful learning in context of MOOC.

\section{ACKNOWLEDGEMENTS}

Special appreciation to the lecturers at the Kaliyah of Education, International Islamic University Malaysia and Faculty of Educational Studies, University Putra Malaysia in allowing us to conduct this research and the presentation of the findings at this conference. Correspondingly, the cooperation of professional experts and field experts from all universities which involved in this research.

\section{REFERENCES}

Baheiraei, A., et.al. (2013). Psychometric properties of the adolescent health concern inventory: the Persian version. Journal of Psychiatry, 8(1), pp. 2836.

Cohen, R.J. \& Swerdlik, M.E. (2010). Psychological Testing and Assessment: An Introduction to Test and Measurement. Ed. Ke-8. Boston: McGrawHill.

Cartwright T. J. \& Atwood J. (2014) Elementary preservice teachers' response-shift bias: Self efficacy and attitudes toward science.
International Journal of Science Education, 36, pp. $2421-2437$.

Din, R. (2010). Development And Validation Of An Integrated Meaningful Hybrid ETraining (IMet) For Computer Science: Theoretical Empirical Based Design And Development Approach. PhD Thesis. Bangi: UKM.

Delgado-Rico, E., et.al. (2012). Content-related validity evidence in test development. International Journal of Clinical and Health Psychology, 12(3), pp. 449-460.

Dewi Rooslani Tojib \& Ly-Fie Sugianto (2006). Content validity of instruments in IS research. Journal of Information Technology Theory Applications, 8(3), pp. 31-56.

Jonassen, D.H., et.al. (1999). Learning with technology: A Constructivist Perspective. NJ: Merrill Prentice Hall.

Johnson, B. \& Christensen, L. (2012). Educational research quantitative, qualitative, and mixed approaches. Alabama: SAGE Publications Inc.

Lawshe, C.H. (1975). A quantitative approach to content validity. Journal of Personality and Social Psychology, 28(4), pp. 563- 575.

Lewis, B.R., et.al. (2005). A methodology for construct development in MIS research. European Journal of Information System, 14(4), pp. 388-400.

Miller, L.A., et.al. (2013). Foundations of psychological testing: a practical approach. California: SAGE Publications Inc.

Ministry of Education Malaysia. (2015). MOOC: Massive Open Online Course. Putrajaya. KPM.

Norashady, M. N., et. al. (2016). Measuring the content validity of MEPO using content validity ratio. Journal of ICT in Education, 3, pp. 81-88.

Rubio, D.M., et. al. (2003). Objectifying content validity: Conducting a content validity study in social work research. Social Work Research: Oxford Journals. 27(2), pp. 94-105.

Sekaran, U. \& Bougie, R. (2011). Research methods for business: A skill building approach. New Delhi: John Wiley \& Sons.

Yu-Li Chen. (2014). A study on student self-efficacy and technology acceptance model within an online taskbased learning environment. Journal of Computers, 9(1), pp. 34-43. 